\title{
Heart Muscle Antibodies in Rheumatic Fever and Other Diseases *
}

\author{
Evelyn V. Hess, Chester W. Fink, Angelo Taranta, and \\ MORRIS ZIFF \\ (From the Departments of Internal Medicine [Rheumatic Diseases Unit] and Pediatrics, The \\ University of Texas Southwestern Medical School, and the Arthritis Clinical Study \\ Center, Parkland Memorial Hospital, Dallas, Texas; Irvington House, \\ Irvington-on-Hudson, N.Y.; and the Department of Medicine, New \\ York University School of Medicine, New York, N. Y.)
}

Serum factors reactive with human heart or extracts of human heart have been found by a number of investigators utilizing a variety of immunologic techniques (1-7). Kaplan, Meyeserian, and Kushner ( 8 ) have demonstrated reactive factors in the sera of patients with acute rheumatic fever and certain other diseases by an immunofluorescent technique. The present study, using the immunofluorescent method, was undertaken to determine the relationship of these serum factors to the clinical state of rheumatic fever, with particular reference to the presence of carditis. The influence of recent streptococcal infection and the occurrence of the serum factors in a number of other disease states were also evaluated.

\section{Materials and Methods}

Sera from 624 individuals were examined. The majority of the rheumatic fever, rheumatic heart disease, and congenital heart disease sera were obtained from Irvington House and Montefiore Hospital in New York; other sera were collected from various Dallas hospitals. The normal individuals tested consisted of 51 children between the ages of 5 and 14 without clinical evidence of disease, who were attending a tuberculosis contact clinic, and 15 adult laboratory workers between the ages of 18 and 40. The different disease groups are listed in Ta-

* Submitted for publication October 16, 1963 ; accepted January 2, 1964.

Preliminary reports were presented at the Southern Society for Pediatric Research, 1961, and the Annual Meeting of the American Rheumatism Association, 1962.

This work was supported by medical care grant CRMC-23 and research grant CR-165 from the National Foundation; grants AM-02071, AM-05154, and AM05055 from the U. S. Public Health Service; and also by a grant from the New York Chapter of the Arthritis and Rheumatism Foundation. ble I. The miscellaneous disease group was made up of two patients with cirrhosis, two with gonococcal arthritis, and one patient each with ankylosing spondylitis, Reiter's syndrome, gout, sarcoidosis, macroglobulinemia, hypergammaglobulinemia, infectious mononucleosis, and a drug reaction. Readings were made without knowledge of the diagnosis. In the case of patients from whom several sera were obtained, the result obtained on the first serum tested was tabulated. Sera were stored at $-20^{\circ} \mathrm{C}$.

Heart tissue. Samples of ventricular muscle were obtained at autopsy from the hearts of premature and neonatal infants who had died of noncardiac causes. These were quick-frozen in a dry vial immersed in acetone and dry ice and stored at $-30^{\circ} \mathrm{C}$ until used. When known positive sera consistently failed to react with the occasional specimen of heart tissue, this tissue was discarded.

Tissue powders. Heart, liver, and diaphragm were obtained at autopsy from a young adult who had died in an accident. These organs as well as rat liver and kidney were acetone dried by the method of Kaplan (9). Sera and conjugates were absorbed with $100 \mathrm{mg}$ per $\mathrm{ml}$ of the appropriate powder for 1 hour at room temperature.

Antigamma globulin conjugate. Antihuman gamma globulin serum was obtained by intramuscular injection of rabbits on 3 consecutive weeks with a total of $3 \mathrm{mg}$ of human Fraction II ${ }^{1}$ and Freund's adjuvant. The globulin fraction of this antiserum was conjugated with fluorescein isothiocyanate according to the technique of Marshall, Eveland, and Smith (10). Conjugates were absorbed before use with the rat tissue powders.

Staining procedure. Tissue sections were cut at $4 \mu$ in a cryostat, thawed on a slide, and fixed in acetone for 10 minutes at room temperature. The sections were then air-dried and given a final rinse in buffered saline. Test serum was applied to the sections for 1 hour in a moist chamber; the slides were then washed for 10 minutes in three changes of buffered saline and incubated with the conjugated antihuman gamma globulin for 30 minutes. The slides were again washed, drained, and the sections mounted in buffered glycerol.

\footnotetext{
${ }^{1}$ Squibb and Company, New Brunswick, N. J.
} 
TABLE I

Heart antibodies in various conditions

\begin{tabular}{|c|c|c|c|c|c|}
\hline Category & $\begin{array}{l}\text { No. indi- } \\
\text { viduals }\end{array}$ & \multicolumn{2}{|c|}{ SS-IMF staining* } & \multicolumn{2}{|c|}{ Diffuse staining } \\
\hline Acute rheumatic fever & 171 & $\begin{array}{c}n o . \\
71\end{array}$ & $\begin{array}{c}\% \\
41.5 \dagger\end{array}$ & $\begin{array}{c}\text { no. } \\
0\end{array}$ & $\begin{array}{l}\% \\
0\end{array}$ \\
\hline $\begin{array}{l}\text { Rheumatic subjects (inactive) } \\
\text { With heart disease } \\
\text { Without heart disease }\end{array}$ & $\begin{array}{r}201 \\
66 \\
135\end{array}$ & $\begin{array}{r}33 \\
8 \\
25\end{array}$ & $\begin{array}{l}16.4 \dagger \\
12.1 \\
18.5\end{array}$ & $\begin{array}{l}0 \\
0 \\
0\end{array}$ & $\begin{array}{l}0 \\
0 \\
0\end{array}$ \\
\hline Miscellaneous diseases & 12 & $\mathbf{0}$ & 0 & 0 & 0 \\
\hline Miscellaneous cardiac diseases & 39 & 2 & 6.3 & 8 & 20.5 \\
\hline Acute glomerulonephritis & 26 & 2 & 7.7 & 2 & 7.7 \\
\hline Connective tissue diseases & 40 & 0 & 0. & 4 & 10.0 \\
\hline Normal individuals & 66 & 2 & 3.0 & 3 & 4.5 \\
\hline
\end{tabular}

* SS-IMF = subsarcolemmal-intermyofibrillar.

$\dagger \mathrm{p}<0.001$.

A Reichert ultraviolet microscope with an Osram HBO-200 mercury lamp, 2-mm Corning 5840 filter, and a red-excluding BG-14 filter was used for viewing the sections.

Specificity of the reactions was demonstrated by negative results using conjugated antisera to heterologous gamma globulin and by partial or complete inhibition with unconjugated antihuman gamma globulin.

Readings. The slides were read independently by two observers. The degree of fluorescence was graded on a 0 to $4+$ scale, $2+$ fluorescence being required for a positive reading. This standard was adopted when experience showed that \pm to $1+$ degrees of fluorescence were difficult to interpret consistently. Disagreement occurred on $3 \%$ of the total of 1,287 slides, mainly where a distinction between 1 and $2+$ fluorescence had to be made. These slides were again examined independently, and the rare slides on which the observers were not then in agreement were discarded. The sera were retested at a later date. There was complete agreement between observers on all of the negative slides read. Throughout the study, many sera were repeatedly tested with consistent results.

\section{Results}

Patterns of staining. In this study, three distinct patterns of staining were noted, as previously reported by Kaplan and associates (8). These patterns are hereafter referred to as sarcolemmal-subsarcolemmal (SS), intermyofibrillar (IMF), and diffuse. Staining of the nucleus was noted with sera from a number of patients with various connective tissue diseases. SS staining was visible as fluorescence along the edges of the myofibers. Intermyofibrillar staining was characterized by very thin lines of fluorescence between the individual myofibrils. The entire myofiber was stained in the diffuse pattern. In the tables that follow, positive reactions refer to the sarcolemmal-subsarcolemmal or intermyofibrillar patterns, or both, and unless otherwise stated will be designated as SS-IMF. Intermyofibrillar staining alone was rarely observed. Whether these reactions represent the presence of antigenically similar components of the myofiber is unclear. Favoring this hypothesis is the observation that one or the other or both types of staining were noted at different times when the same sera were applied to various heart specimens. The possibility that they represent different antigens cannot, however, be excluded.

The above terminology utilized to indicate the myocardial reaction sites is necessarily tentative, since the levels of magnification available in fluorescence microscopy do not allow a more specific or detailed localization. Recent electron microscopy studies $(11,12)$ have demonstrated that the sarcolemma is a complex structure that consists of as many as four separate layers not only surrounding the myofiber but also forming an extensive connecting system around and between the individual myofibrils. The subsarcolemmal and intermyofibrillar areas also contain sarcoplasmic components and mitochondria.

Acute rheumatic fever. In Table I the results in 171 patients with acute rheumatic fever and 201 inactive rheumatic subjects are compared with the various control groups. The diagnosis of acute rheumatic fever was established according to the modified Jones criteria (13). Two- 
TABLE II

Relationship of heart antibodies to cardiac status in rheumatic fever

\begin{tabular}{lccc}
\hline \multicolumn{1}{c}{ Cardiac status } & $\begin{array}{c}\text { No. } \\
\text { patients }\end{array}$ & $\begin{array}{c}\text { No. } \\
\text { positive }\end{array}$ & $\begin{array}{c}\% \\
\text { positive }\end{array}$ \\
\hline Carditis present & 71 & 45 & $63.4^{*}$ \\
Carditis absent & 74 & 19 & $26.0^{*}$ \\
Carditis doubtful & 26 & 7 & 26.9 \\
\hline
\end{tabular}

${ }^{*} \mathrm{p}<0.001$

thirds of the acute rheumatic fever group were in their initial attack. In this group the SS-IMF type of staining was observed in 71 or $41.5 \%$ of the patients. Of 66 subjects with inactive rheumatic heart disease, 8 , or $12.1 \%$, showed positive results. Twenty-five, or $18.5 \%$, of the 135 rheumatic subjects without evidence of rheumatic heart disease were positive. The difference between the acute rheumatic fever group and the combined group of inactive rheumatic subjects was highly significant $(\mathrm{p}<0.001)$.

Miscellaneous diseases. The sera of all 12 patients in the miscellaneous diseases category failed to react. Two of the 26 patients with acute glomerulonephritis exhibited SS-IMF staining; two, diffuse staining. SS-IMF staining was not noted among the 40 patients with connective tissue diseases, although 4 showed diffuse staining. In the normal group, $3.0 \%$ demonstrated the SS-IMF and $4.5 \%$ the diffuse pattern of staining. All of the 5 individuals in whom these findings occurred were children with no evidence of disease.

Rheumatic carditis. The 171 patients with active rheumatic fever were further subdivided into those with carditis, without carditis, and with doubtful carditis (Table II). The doubtful carditis group consisted chiefly of patients with soft systolic murmurs of questionable significance and other nonspecific findings. Of the 71 patients with carditis, $63.4 \%$ reacted with the SS-IMF components, whereas only $26.0 \%$ of the 74 patients without clinical evidence of carditis were reactive. This difference is highly significant. In 26 patients with doubtful carditis, $26.9 \%$ were reactive.

The incidence of positive reactions (Table III) was greater in patients with carditis experiencing at least the second episode of rheumatic fever $(75.0 \%)$ than in those in their first attack $(52.9 \%)$. In the patients without carditis, $17.8 \%$ were positive in the first attack and $31.3 \%$ in subsequent attacks, indicating a similar relationship. The differences in both cases, however, were not statistically significant.

A group of 65 patients (Table IV) tested during the first attack was subsequently examined 1 year or more afterward. There was a suggestion that the patients with definite carditis and a positive serum reaction had a higher incidence of rheumatic heart disease on follow-up ( 9 of 15 , or $60 \%$ ) than a similar group with a negative serum reaction ( 4 of 11 , or $36 \%$ ). A larger number of patients will be needed to clarify this point.

Relation to antistreptolysin-O titer. The relationship of this titer to the serum factors was studied in 160 patients with rheumatic fever (Table V). Both the ASO titer and heart antibodies were tested on the same specimen in most patients; in a few, the procedures were performed on specimens obtained within a few days of each other. In most instances, the samples were taken in the first week of admission to the hospital. The two groups of patients with ASO titers of 0 to 125 and 166 to 250 each had $44 \%$ positive reactions. Thirty-five per cent of the 60 patients with titers of 333 to 625 and $18 \%$ of the 11 patients with titers over 625 were positive. These values are not significantly different. Significant differences were also not observed

TABLE III

Relationship of heart antibodies to carditis and to number of attacks of rheumatic fever

\begin{tabular}{lccccccc}
\hline \hline & \multicolumn{3}{c}{ With carditis } & & \multicolumn{3}{c}{ Without carditis } \\
\cline { 2 - 4 } \cline { 6 - 8 } No. of attacks & $\begin{array}{c}\text { No. } \\
\text { patients }\end{array}$ & $\begin{array}{c}\text { No. } \\
\text { positive }\end{array}$ & $\begin{array}{c}\% \% \\
\text { positive }\end{array}$ & & $\begin{array}{c}\text { No. } \\
\text { patients }\end{array}$ & $\begin{array}{c}\text { No. } \\
\text { positive }\end{array}$ & $\begin{array}{c}\% \\
\text { positive }\end{array}$ \\
\hline Initial & 34 & 18 & $52.9^{*}$ & & 45 & 8 & $17.8^{*}$ \\
Two or more & 24 & 18 & $75.0^{*}$ & & 16 & 5 & $31.3^{*}$ \\
\hline
\end{tabular}

${ }^{*} \mathrm{p}>0.05$. 
TABLE IV

Relationship of heart antibodies and carditis to subsequent rheumatic heart disease

\begin{tabular}{lccc}
\hline Cardiac status & $\begin{array}{c}\text { SS-IMF } \\
\text { staining }\end{array}$ & $\begin{array}{c}\text { No. } \\
\text { patients }\end{array}$ & $\begin{array}{c}\text { No. with } \\
\text { subsequent } \\
\text { heart } \\
\text { disease }\end{array}$ \\
\hline Carditis present & + & 15 & 9 \\
Carditis absent & + & 11 & 4 \\
Carditis doubtful & + & 53 & 0 \\
& - & 2 & 1 \\
\hline
\end{tabular}

when patients were divided into those with carditis and those without carditis. Obviously a single ASO titer does not indicate the magnitude of the immune response, and a more detailed serial study might show evidence of a relationship.

Relation to streptococcal infection. In a group of patients attending the prophylactic clinic at Irvington House, 32 (not included in previous tables) who had previously had one or more attacks of rheumatic fever developed streptococcal infections without evidence of a new episode. Sera were available before, during, and after the streptococcal infection. The time interval between the pre- and postinfection sera ranged between 6 and 22 weeks (average, 13 weeks). All three sera were negative in 19 , or $59.4 \%$, of the patients. In 7 patients, the preinfection serum was negative but one or both of the subsequent sera were positive. In the remaining 6 patients, the preinfection serum was positive, and of these, 5 became negative during infection and in the postinfection period. The remaining patient became negative during infection but reverted to positive in the postinfection period. The three groups did not differ in the frequency of previous carditis.

TABLE V

Relationship of heart antibodies to antistreptolysin- $O$ titer in rheumatic fever

\begin{tabular}{rcc}
\hline ASO titer & No. patients & $\%$ positive \\
\hline $0-125$ & 39 & $44^{*}$ \\
$166-250$ & 50 & 44 \\
$333-625$ & 60 & 35 \\
$>625$ & 11 & $18^{*}$ \\
\hline
\end{tabular}

${ }^{*} \mathrm{p}>0.05$.
TABLE VI

Heart antibodies in rheumatic and congenital heart disease before and after cardiac surgery

\begin{tabular}{llcc}
\hline $\begin{array}{c}\text { Before } \\
\text { surgery }\end{array}$ & $\begin{array}{c}\text { After } \\
\text { surgery }\end{array}$ & $\begin{array}{c}\text { Rheu- } \\
\text { matic } \\
\text { heart } \\
\text { disease }\end{array}$ & $\begin{array}{c}\text { Congen- } \\
\text { ital } \\
\text { heart } \\
\text { disease }\end{array}$ \\
\hline Negative & Positive & 10 & 1 \\
Negative & Negative & 6 & 15 \\
Positive & Positive & 2 & 0 \\
Positive & Negative & 1 & 2 \\
\hline
\end{tabular}

Results in consecutive sera during rheumatic fever attacks. In each of 19 patients with acute rheumatic fever, at least four sera were obtained at weekly or biweekly intervals after the onset of the acute attack. In 8 patients, all sera were nonreactive. In 9, serum factors were first detected between the second and fifth weeks after the first clinical manifestations of the acute attack, and in 2 these appeared by the sixth and seventh weeks. The sera of 5 of the patients with rheumatoid arthritis were also tested serially and were consistently negative.

Effect of surgery in congenital and rheumatic heart disease. Sera from 18 patients with congenital heart disease and 19 patients with rheumatic heart disease were tested before and after cardiac surgery (Table VI). The postoperative sera were obtained between the eighth and tenth days. The sera of 10 of 16 patients with rheumatic heart disease that showed negative reactions preoperatively gave positive reactions when examined postoperatively. In contrast, only 1 of 16 patients with congenital heart disease showed a similar change $(p<0.01)$. One of two rheumatic heart disease sera and two congenital heart disease sera changed from positive to negative.

Miscellaneous heart disease. Two of the 39 patients (Table VII) with miscellaneous heart diseases demonstrated the SS-IMF type of staining. One of these had heart disease of unknown etiology and the second a myocardial infarction. Eight of the group, however, showed a diffuse type of staining. This occurred in 6 of the 22 patients with myocardial infarction, in 1 patient with diphtheritic myocarditis, and 1 with Marfan's syndrome accompanied by pericarditis and myocarditis. All the sera from patients with myocardial infarction were obtained within a 3- 
TABLE VII

Heart antibodies in miscellaneous cardiac diseases

\begin{tabular}{|c|c|c|c|}
\hline & \multirow[b]{2}{*}{$\begin{array}{c}\text { No. } \\
\text { patients }\end{array}$} & \multicolumn{2}{|c|}{$\begin{array}{l}\text { No. with } \\
\text { positive staining }\end{array}$} \\
\hline & & $\begin{array}{l}\text { SS- } \\
\text { IMF }\end{array}$ & Diffuse \\
\hline Myocardial infarction & 22 & 1 & 6 \\
\hline Viral pericarditis & 4 & $\mathbf{0}$ & $\mathbf{0}$ \\
\hline Congenital heart disease & 3 & $\mathbf{0}$ & $\mathbf{0}$ \\
\hline Diphtheritic myocarditis & 2 & $\mathbf{0}$ & 1 \\
\hline Heart disease of unknown etiology & 2 & $1^{*}$ & $\mathbf{0}$ \\
\hline $\begin{array}{l}\text { Hypertensive or arteriosclerotic } \\
\text { heart disease }\end{array}$ & 2 & $\mathbf{0}$ & $\mathbf{0}$ \\
\hline Traumatic pericarditis & 1 & $\mathbf{0}$ & $\mathbf{0}$ \\
\hline Sarcoid myocarditis & 1 & $\mathbf{0}$ & $\mathbf{0}$ \\
\hline $\begin{array}{l}\text { Marfan's syndrome with pericarditis } \\
\text { and myocarditis }\end{array}$ & 1 & $\mathbf{0}$ & 1 \\
\hline Beriberi heart disease & 1 & $\mathbf{0}$ & $\mathbf{0}$ \\
\hline
\end{tabular}

* Suspected, but not proven, sarcoidosis with heart disease.

week period after the probable date of infarction. The positive reactions in this group, occurring in $30 \%$ of the individuals tested, were noted in sera drawn at random times between the fourth and twenty-first days after infarction. The earliest positive reaction was noted in a 33-year-old female tested 4 days after a second episode of infarction.

Connective tissue diseases. Four of the 25 patients with rheumatoid arthritis showed diffuse staining (Table VIII). Five patients with juvenile rheumatoid arthritis were included in this group, and 3 had clinical evidence of myocarditis at the time the serum was tested, but all gave negative tests. SS-IMF staining was not observed in any of the patients with connective tissue disease although a number had cardiac involvement.

Tissue absorptions. The specificity of the fluorescent staining reaction was demonstrated by absorption of positive sera from patients with

TABLE VIII

Heart antibodies in connective tissue diseases

\begin{tabular}{lcc}
\hline \hline & $\begin{array}{c}\text { No. pa- } \\
\text { tients }\end{array}$ & $\begin{array}{c}\text { No. pos- } \\
\text { itive* }\end{array}$ \\
\hline Rheumatoid arthritis & 25 & 4 \\
Systemic lupus erythematosus & 8 & 0 \\
Scleroderma & 2 & 0 \\
Polymyositis & 2 & 0 \\
Idiopathic thrombocytopenia & 1 & 0 \\
Mixed connective tissue disease & 1 & 0 \\
Polyarteritis nodosa & 1 & 0 \\
\hline
\end{tabular}

* Diffuse staining pattern. acute rheumatic fever and myocardial infarction with human liver, heart, and skeletal muscle powders. Absorption with human liver powder did not abolish or reduce reactivity. Absorption with either human heart or skeletal muscle powder, however, markedly decreased or completely abolished all three types of staining. Where sera showing the diffuse pattern of staining were absorbed, there was no evidence of change in the appearance of the pattern to SS-IMF staining.

\section{Discussion}

This study confirms and extends previous evidence for the occurrence of factors in human serum that are reactive with heart muscle constituents. Reactions with SS and IMF components were common in inactive rheumatic subjects, in a few patients with miscellaneous cardiac diseases, a few with acute glomerulonephritis, and in $3 \%$ of normal individuals. A diffuse staining pattern was noted in patients with several types of heart disease, mainly myocardial infarction, in some patients with rheumatoid arthritis, some with acute glomerulonephritis, and in $4.5 \%$ of a normal group.

The percentage of positive SS-IMF reactions was considerably higher in acute rheumatic fever than in any of the other diseases, being highest in patients with clinically active carditis. The relatively decreased incidence of positive reactions in a large group of inactive rheumatic subjects, with and without rheumatic heart disease, indicates that these serum factors do not persist in the serum indefinitely.

Kaplan and associates (8), also using the immunofluorescent technique, found that $77.4 \%$ of 40 patients with acute rheumatic fever gave positive reactions in comparison with the value of $41.5 \%$ we observed. These authors noted all three types of staining patterns, but in contrast to the findings in our group with acute rheumatic fever, in which the diffuse pattern was not seen, $52 \%$ of their patients showed diffuse staining. Their higher figure may result from the fact that their results were not restricted to a single serum specimen from each patient and that a lesser degree of fluorescence $(1+)$ was regarded as significant. The variation may also result from the difference in the type of heart tissue utilized; neo- 
natal heart was used in the present study and adult heart by Kaplan and associates (8).

The extent to which the results in patients with rheumatic carditis correlate with myocardial rather than endocardial involvement is of some interest. Unfortunately, clinical criteria are not sufficiently accurate to establish such a differentiation. In some of the patients classified as having "no carditis" or "inactive heart disease," undiagnosed myocarditis could have been present. Atrial appendages of patients thought to have inactive rheumatic heart disease have shown the presence of Aschoff bodies, which are generally regarded as evidence of activity (14).

A comparison of patients undergoing cardiac surgery for either rheumatic or congenital heart disease revealed a marked difference in the number of positive reactions in these groups between the eighth and tenth days after surgery. The large percentage of positive findings at this time in the rheumatic heart disease group may represent a secondary response to cardiac antigens released at the time of surgery. Congenital heart disease patients, on the other hand, presumably exposed to released antigens for the first time during surgery, would not be expected to have a high percentage of positive reactions at that time. Kaplan and co-workers (8) have observed SS staining in a few patients with pulmonary disease after thoracotomy and SS-IMF staining in patients with liver disease. The mechanisms whereby factors capable of reacting with cardiac antigens are released under these conditions are not clear.

In the present series, 7 of 22 patients with myocardial infarction had heart antibodies. Ehrenfeld, Gery, and Davies (15), using a tanned cell technique employing cells sensitized with saline extracts of cardiac tissue, found antibodies in 12 of 53 patients with myocardial infarcts. Since damage to the cardiac myofiber occurs in this disease, these findings suggest that release of antigen as a consequence of damage to the myofiber is a feature of both rheumatic carditis and myocardial infarction, the two diseases giving the highest percentage of positive reactions.

Because of insufficient subjects, we could not evaluate the relationship between the presence of serum factors in patients with carditis and the subsequent incidence of rheumatic heart disease.
There appeared to be no relationship to the ASO titer in the rheumatic fever group. As already pointed out, however, the immunofluorescent findings were correlated with only one ASO determination and, therefore, not always with the maximal ASO response.

The data in the 32 rheumatic subjects having acute streptococcal infections without development of rheumatic fever did not suggest a relationship between exposure to group A streptococci and the subsequent appearance of serum factors reactive with heart, as might be expected from the experiments of Kaplan and Meyeserian (16), who have recently shown that the serum of rabbits immunized with the cell walls of certain strains of group A streptococci react with human myocardium. Nineteen of this group of patients were negative on all three tests, and 6 who were positive initially became negative after infection. Only 7 of the 32 developed positive tests. Since this group of patients exhibited a $16.4 \%$ incidence of heart antibodies when examined at random, it is unlikely that the latter change is necessarily significant.

Both Kaplan and co-workers (8) and we have demonstrated by absorption procedures that the antigens stained by the immunofluorescent procedure are present in cardiac and in skeletal muscle. It has also been shown by the immunofluorescent technique that the cardiac muscle antigens are both alcohol $(8,17)$ and water soluble (17). Other investigators $(1-4,7,8,15)$ have utilized alcohol, saline, and water soluble extracts of heart for the detection of heart antibodies by other procedures. Whether the antigens involved in these various studies are the same is still unknown.

The fluorescence patterns observed in our study have indicated reactions with different constituents of the myofiber. SS-IMF staining was noted predominantly in patients with rheumatic fever and rheumatic heart disease. The diffuse type of staining was observed in nonrheumatic subjects, most commonly patients with myocardial infarction, and may reflect a different antigen. That diffuse staining is a more widespread and intense form of SS-IMF staining is unlikely for two reasons. First, diffuse staining was characteristic of certain disease states like myocardial infarction and not of others like rheumatic fever, 
where it was never observed. In the patients with myocardial infarction, 15 of 22 showed no staining at all, although 6 of the 7 positive individuals showed diffuse staining. Secondly, when sera with diffuse staining were absorbed with human heart or skeletal muscle powder, there was no reversion of diffuse staining to the SS-IMF variety as the diffuse staining pattern disappeared. These observations do not appear consistent with the possibility that SS-IMF staining is an attenuated form of diffuse staining. The occurrence of yet other types of muscle antibodies has recently been demonstrated in some patients with myasthenia gravis who have been shown to possess serum factors reactive with both voluntary and cardiac muscle cross-striations (18-20).

It is unlikely that the serum factors under discussion are nonspecific, acute phase reactants, since they were present in inactive as well as active rheumatic subject but not in patients with a variety of acute inflammatory diseases. Also, Kushner, Rakita, and Kaplan (21) observed that $\mathrm{C}$-reactive protein in infarcted rabbit hearts was localized to the necrotic area, where it was present at the outer edge of myofibers as well as in the form of inclusions within the substance of necrotic myofibers.

The evidence favors the conclusion that these factors are serum antibodies, although final proof is lacking. They are gamma globulins as indicated by their immunofluorescent reactivity, and they have been shown to exist in both 7S and 19S forms in rheumatic fever serum $(8,17)$. Their reactivity appears to be directed at one or more components of normal cardiac and skeletal muscle. Finally, they may be absorbed by muscle powders and extracts of muscle but not by preparations derived from liver.

\section{Summary}

1. Serum factors reactive with human heart muscle were investigated by the indirect immunofluorescent technique in a total of 624 subjects. Two main staining patterns were observed: sarcolemmal-subsarcolemmal and diffuse; an intermyofibrillar pattern was also seen.

2. In acute rheumatic fever, $41.5 \%$ of the patients showed the sarcolemmal-subsarcolemmal pattern, the latter at times accompanied by inter- myofibrillar staining. In the presence of carditis, this percentage increased to $63.4 \%$. Only $16.4 \%$ of a group of inactive rheumatic subjects gave positive reactions.

3. Twenty-seven per cent of 22 patients with myocardial infarction showed the diffuse type of immunofluorescent reaction; only 1 patient gave the sarcolemmal-subsarcolemmal pattern. The diffuse staining pattern was also occasionally seen in patients with acute glomerulonephritis and rheumatoid arthritis.

4. Other groups, including 66 normal subjects, showed a low incidence of positive reactions.

5. There was a striking increase in incidence of positive reactions after cardiac surgery for rheumatic heart disease as compared with congenital heart disease.

6. There appeared to be no relationship between the incidence of positive reactions and antistreptolysin-O titer.

7. The evidence indicates that the serum factors are antibody in nature.

\section{Acknowledgments}

The authors wish to express appreciation for the capable technical assistance of Miss Jean Dealy and Mr. George Jones.

\section{References}

1. Brokman, H., J. Brill, and J. Frendzel. Komplementablenkung mit Organextrakten von Rheumatikern-BBF.-Reaktion-bei sogenanntem akutem Glenkrheumatismus. Klin. Wschr. 1937, 16, 502.

2. Cavelti, P. A. Autoantibodies in rheumatic fever. Proc. Soc. exp. Biol. (N. Y.) 1945, 60, 379.

3. Osler, A. G., P. H. Hardy, and J. T. Sharp. The fixation of complement by human sera and alcoholic extracts of human cardiac tissue. Amer. J. Syph. 1954, 38, 554.

4. Rejholec, V., and V. Wagner. Antimyocardial antibodies in rheumatic fever. Experientia (Basel) 1955, 11, 278.

5. Butler, K. R., and S. Moeschlin. Antikörper gegen verschiedene Gewebszellen bei rheumatischen und anderen Erkrankungen. Helv. med. Acta 1956, 23, 592.

6. Steffen, C. Nachweis und Wirkung von GewebsAutoantikörpern bei primär-chronischer Polyarthritis im Vergleich mit anderweitig auftretenden Gewebs-Autoantikörpern in Immunopathology, 1st International Symposium, P. Grabar and P. Miescher, Eds. Basel, Benno Schwabe, 1958, p. 376.

7. Gery, I., A. M. Davies, and E. N. Ehrenfeld. Heartspecific autoantibodies. Lancet 1960, 1, 471. 
8. Kaplan, M. H., M. Meyeserian, and I. Kushner. Immunologic studies of heart tissue. IV. Serologic reactions with human heart tissue as revealed by immunofluorescent methods: isoimmune, Wassermann, and autoimmune reactions. J. exp. Med. 1961, 113, 17.

9. Kaplan, M. H. Immunologic studies of heart tissue. I. Production in rabbits of antibodies reactive with an autologous myocardial antigen following immunization with heterologous heart tissue. J. Immunol. 1958, 80, 254.

10. Marshall, J. D., W. E. Eveland, and C. W. Smith. Superiority of fluorescein isothiocyanate (Riggs) for fluorescent-antibody technic with a modification of its application. Proc. Soc. exp. Biol. (N. Y.) 1958, 98, 898.

11. Mauro, A., and W. R. Adams. The structure of the sarcolemma of the frog skeletal muscle fiber. J. biophys. biochem. Cytol. 1961, 10 (suppl.), 177.

12. Nelson, D. A., and E. S. Benson. On the structural continuities of the transverse tubular system of rabbit and human myocardial cells. J. cell Biol. 1963, 16, 297.

13. The treatment of acute rheumatic fever in children. A cooperative clinical trial of ACTH, cortisone and aspirin. Circulation 1955, 11, 343.

14. Dalldorf, F. G., and G. E. Murphy. Relationship of Aschoff bodies in cardiac atrial appendages to the natural history of rheumatic heart disease. Amer. J. Path. 1960, 37, 507.

15. Ehrenfeld, E. N., I. Gery, and A. M. Davies. Specific antibodies in heart-disease. Lancet 1961, 1, 1138.

16. Kaplan, M. H., and M. Meyeserian. An immunological cross-reaction between group-A streptococcal cells and human heart tissue. Lancet 1962, 1, 706.

17. Hess, E. V., C. W. Fink, and J. Dealy. Unpublished observations.

18. Strauss, A. J. L., B. C. Seegal, K. C. Hsu, P. M. Burkholder, W. L. Nastuk, and K. E. Osserman. Immunofluorescence demonstration of muscle binding, complement-fixing serum globulin fraction in myasthenia gravis. Proc. Soc. exp. Biol. (N. Y.) 1960, 105, 184.

19. Beutner, E. H., E. Witebsky, D. Ricken, and R. H. Adler. Studies on autoantibodies in myasthenia gravis. J. Amer. med. Ass. 1962, 182, 46.

20. Hess, E. V., J. P. Grigson, S. Eliasson, and M. Ziff. Lupus erythematosus, antinuclear, and antimuscle factors in myasthenia gravis (abstract). J. Lab. clin. Med. 1962, 60, 884.

21. Kushner, I., L. Rakita, and M. H. Kaplan. Studies of acute-phase protein. II. Localization of Cx-reactive protein in heart in induced myocardial infarction in rabbits. J. clin. Invest. 1963, 42, 286. 